\title{
FLOOD ANALYSIS WITH REMOTE SENSING DATA - A CASE STUDY: MARITSA RIVER, EDIRNE
}

\author{
A. F. Sunar ${ }^{1, *}$, N. Yagmur $^{1}$, A. Dervisoglu ${ }^{1}$ \\ ${ }^{1}$ Istanbul Technical University, Civil Engineering Faculty, Geomatics Engineering Department, 34000, Maslak Istanbul, Turkey - \\ (fsunar, yagmurn, adervisoglu)@itu.edu.tr
}

KEY WORDS: Maritsa-Evros Basin, Flood, Remote Sensing, Sentinel 1/ 2 Data, GEE

\begin{abstract}
:
A flood, one of the most devastating natural disasters in the world, occurs when water inundates land that's normally dry. Although floods can develop in many ways, river floods (i.e. overflow by rivers or river banks) are the most common. Turkey is one of the flood-affected countries with its 20 main basins in 8 regions. One of the most aggrieved basins in Turkey is the Maritsa river basin in in Eastern Balkans, which also contains the natural border regions with Greece and Bulgaria. 65\% of the Maritsa River basin, which originates from the Rila Mountains and joins the Arda and Tundzha rivers, is located in Bulgaria. When the melting snow flow or precipitation in the basin increases, the Maritsa River overflows from the slopes to the Edirne Plain and from time to time exceeds the capacity of the bed, causing floods. On the other hand, since the water level in the dams and reservoirs was kept at the highest level for production purposes, the flood repeat interval increased in the region, since 2000s. Today, it is possible to monitor and evaluate the damages of flood by obtaining very reliable information with space technology. Especially, microwave SAR images that can penetrate clouds, are of great importance in flood mapping because they provide immediate information on the extent of inundation and support the evaluation of property and environmental damages. In this study, rapid flood risk assessment in the region was performed using Landsat 8 and Sentinel 2 Normalized Difference Water Index (NDWI) time series images, and calibrated Sentinel 1 SAR images produced on Google Earth Engine (GEE) platform for 2015-2018 period. GEE is a cloud-based platform that facilitates access to high-performance computing resources to handle very large geographic data sets. The results were compared and verified using meteorological data, riverbed flow data, and digital media news. The results showed that the most affected areas were consistent with the highest measured flow rates and the magnitude of flood damages caused by two main causes in the basin (i.e. opening of shutters in Bulgarian dams or local excessive rainfall) was very different (approximately 8 times larger) from each other.
\end{abstract}

\section{INTRODUCTION}

Floods, which have serious environmental and social impacts worldwide, have been mostly caused by climate-related factors such as severe spring snowmelt and heavy rainfall in the last decade (CRED, 2015).

Turkey is one of the countries affected by the floods with its 20 main basins in eight regions. One of the most aggrieved basins in Turkey is the Maritsa (Meriç in Turkish) river basin, located in Eastern Balkans containing the natural boundary regions with Greece and Bulgaria (INWEB, 2019). River floods in this basin where three rivers meet (biggest tributaries, Tundzha and Arda Rivers, joining in Maritsa in Edirne) are among the most common examples, due to excessive rainfall or snowmelt as well as uncontrolled water released from existing dams in Bulgaria and insufficient riverbed cross-sections. A significant number of reservoirs and cascades (about 2.2 billion $\mathrm{m}^{3}$ on the Maritsa and Tundzha Rivers and about 1 billion $\mathrm{m}^{3}$ on the Arda River in Bulgaria) have been built for irrigation and hydroelectricity production (Figure 1). After 1994, with the privatization of dams and hydroelectric power generation, the water level in the reservoirs was kept at the highest level for production purposes and the flood recurrence interval increased after this date (Yildiz, 2011). However, uncontrolled water released from existing dams directly overflows on the Maritsa River, causing serious transboundary floods in Edirne. Research studies have shown that, especially after 2005 , floods, occurred very often, can be prevented with proper implementations and operations of the Bulgarian dams without causing economic loss (Sezen, 2007).

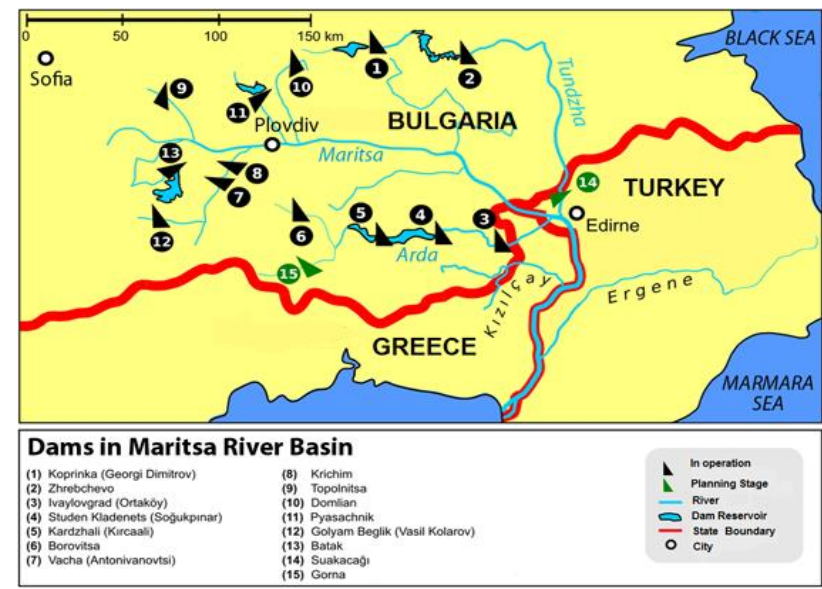

Figure 1. Trans-boundary Maritsa river basin and reservoirs (Yildiz, 2011).

To prevent natural hazards such as flood, geo-information technologies (i.e. remote sensing and GIS) are used as an effective tool for risk assessment and hazard management, providing a synoptic view and faster analysis than conventional surveying methods. Remote sensing systems with both passive optical sensors and active microwave sensors are often used for flood mapping and offer different levels of capacity and accuracy (Shen et. al., 2019) (Figure 2). However, since the

\footnotetext{
* Corresponding author
} 
validity of optical observations is limited by clouds, which are common during flood events, microwave SAR systems are preferred providing more efficient analysis due to their penetration capabilities through the atmosphere (Shen et. al., 2019).

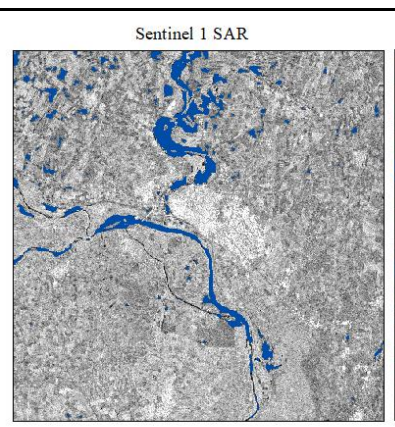

March 27, 2018
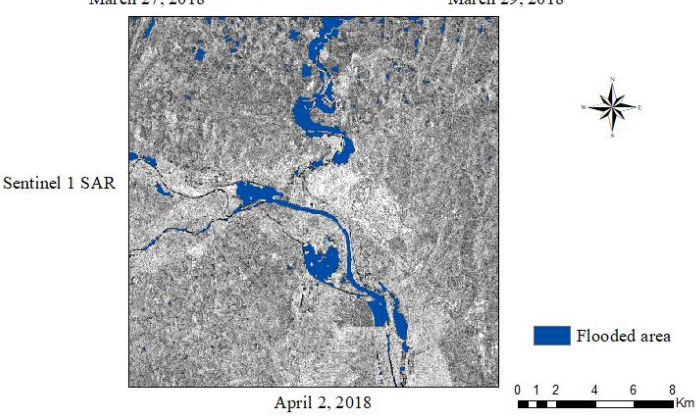

Figure 2. Example of satellite dataset used for the latest flood of March 25, 2018.

This study contributes to the application of cloud computing Google Earth Engine (GEE) and its potential for flood monitoring and mapping. Recently, GEE is being used for environmental data analysis that can determine important parameters from different satellite time series images. In this study, GEE was used to assess potential flood damage by visualizing and plotting the multi-temporal Landsat/Sentinel 2 NDWI and calibrated Sentinel $1 \mathrm{~dB}$ values in time series graphs. The findings were used to assess whether the increase in flood frequency in the region was due to climate change or improper management of Bulgarian dams, together with ancillary data.

\section{STUDY AREA \& DATA USED}

The Maritsa river basin, is one of the major river systems located in the eastern Balkans, with a total length of $550 \mathrm{~km}$ and a total catchment area of $39,000 \mathrm{~km}^{2}$ (Figure 1) (INWEB, 2019). The city of Edirne, located in the North West region of Turkey, lies at the junction of the Tundzha, Arda and Maritsa rivers, near the borders of Greece and Bulgaria. The area of 44544.78 hectares covering Edirne Center was selected as the study area (Figure 3). Since 1571, Edirne city center has witnessed the most recorded floods resulting significant negative environmental and economic impacts with a wide variety of consequences from local to national scales (Turoglu \& Uludag, 2010).

Landsat 8 OLI MSI and Sentinel 2 MSI, which are free optical data since 2013 and 2015, were used as a satellite data set (Table 1). In addition to optical data, Sentinel 1 SAR data, which has been free microwave satellite data since 2014, was used for flood mapping due to its capability of capturing the images day/night, irrespective of the weather conditions. In this study, the period of 2015-2018 was taken into consideration according to the operational dates of Sentinel 2 satellites.

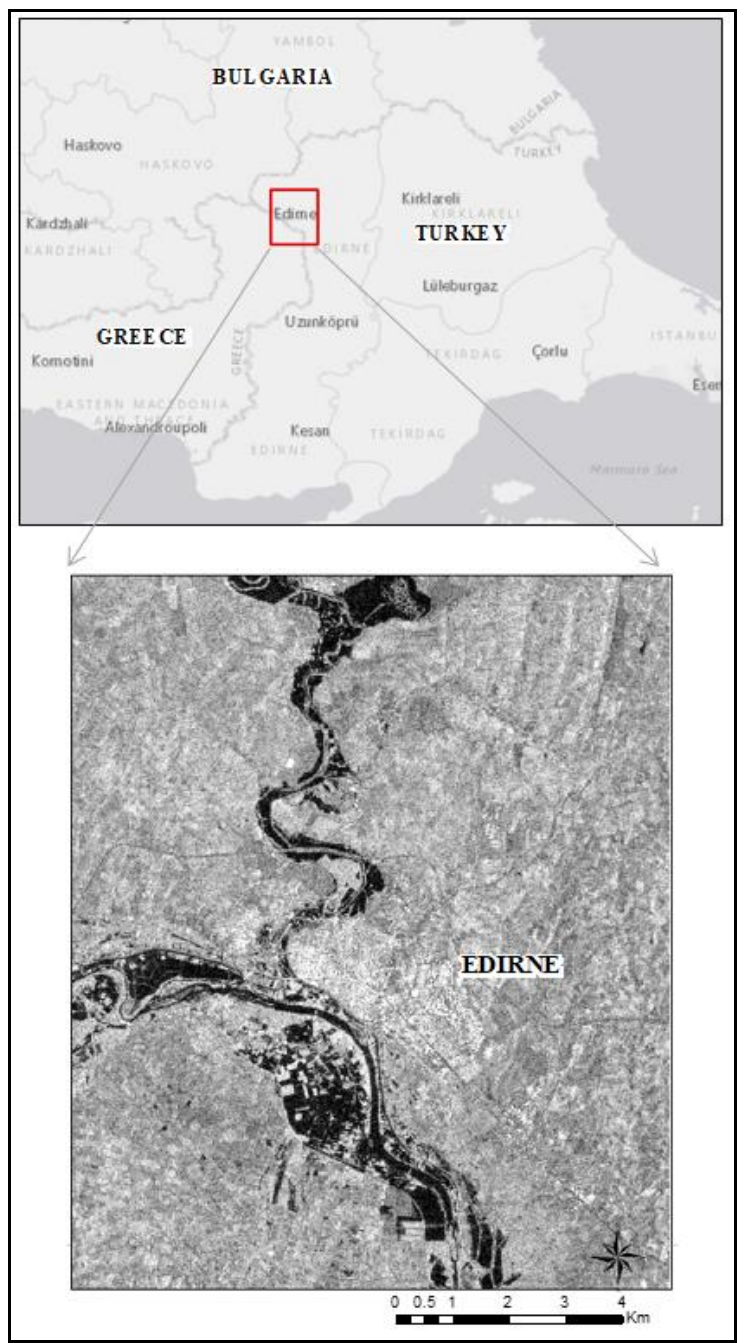

Figure 3. Map of the study area.

\begin{tabular}{|c|c|c|c|c|}
\hline & Satellite & $\begin{array}{c}\text { Landsat } 8 \\
\text { (optical) }\end{array}$ & $\begin{array}{c}\text { Sentinel } 2 \\
\text { (optical) }\end{array}$ & $\begin{array}{l}\text { Sentinel } 1 \\
\text { (SAR) }\end{array}$ \\
\hline \multirow{4}{*}{ 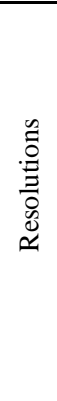 } & $\begin{array}{l}\text { Spectral } \\
(\mu \mathrm{m})\end{array}$ & $\begin{array}{l}9 \text { Bands } \\
(0.433-2.30)\end{array}$ & $\begin{array}{l}12 \text { Bands } \\
(0.443-2.20)\end{array}$ & $\begin{array}{c}\text { C band } \\
(\mathrm{HH}, \mathrm{HV}, \mathrm{VH}, \\
\text { VV) }\end{array}$ \\
\hline & Spatial (m) & $\begin{array}{c}\text { B1-5,7.9: } 30 \mathrm{~m} \\
\text { B6: } 60 \mathrm{~m} \\
\text { B8: } 15 \mathrm{~m}\end{array}$ & $\begin{array}{c}\text { B2,3,4,8:10 m } \\
\text { B5,6,7,8a, } \\
11.12: 20 \mathrm{~m} \\
\text { B1,9,10: } 60 \mathrm{~m}\end{array}$ & $5 \times 20 \mathrm{~m}$ \\
\hline & Radiometric & 6 bit & 12 bit & $10 \mathrm{bit}$ \\
\hline & Temporal & 16 days & 10 days & 12 days \\
\hline
\end{tabular}

Table 1. The characteristics of the satellite data used (Url-1, Url-2).

Meteorological data and flow measurements were also used as anchillary data in the analysis. Precipitation values and flow data were obtained from Edirne Meteorological Station and 5 different flow observation stations, respectively. Research shows that the discharge in Edirne city center should not exceed $1000 \mathrm{~m}^{3} / \mathrm{s}$, otherwise it causes flooding. When the maximum flow values taken from the measurement station in Edirne center 
between 1982 - 2015 are examined; especially after the 2000s, it is seen that the critical flow threshold is often exceeded (Url3) (Figure 4).

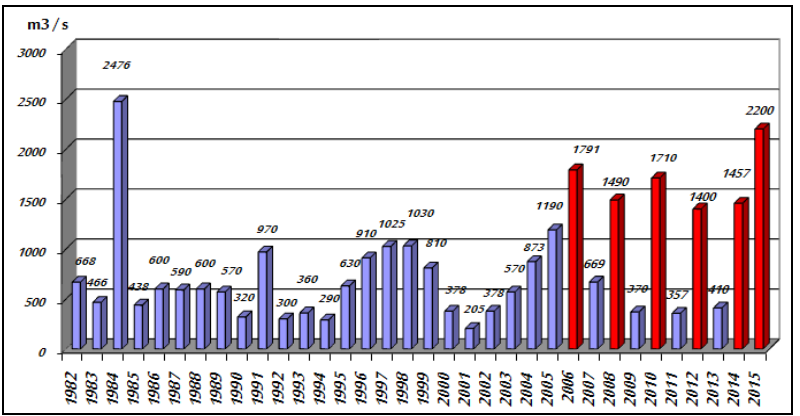

Figure 4. Maximum flow values of Maritsa River measured by DSI between 1982-2015 (Url-3).

\section{METHODOLOGY}

To evaluate the flooding occurance and mapping, the following image processing steps were applied.

\section{- Normalized Difference Water Index (NDWI)}

NDWI is a widely used remote sensing-derived index to monitor changes related to water content (water level or change in water level - e.g. flooding) in water bodies. NDWI uses Green and Near-infrared bands of the satellite images to delineate and enhance open water features (Eq. 1) (McFeeters, 1996).

$$
\text { NDWI }=(\text { Green }- \text { NIR }) /(\text { Green }+ \text { NIR })
$$

\section{- SAR Calibration \& Thresholding}

The purpose of SAR calibration is to provide images in which the pixel values may be directly related to the radar backscatter of the scene. The unitless backscatter coefficient is converted to $\mathrm{dB}$ in order to retrieve an evenly distributed value range from the non-Gaussian distributed values (Eq. 2).

$$
\sigma^{0}(\mathrm{~dB})=10 \times \log _{10} \sigma^{0}
$$

where, $\sigma^{0}(\mathrm{~dB})$; backscattering image in $\mathrm{dB}, \sigma^{0}$; Sigma nought image.

In SAR images, water areas are characterized by low backscatter values since the water surface is smooth. From a statistical point of view, the histogram of water and non-water backscattering values is generally characterized by a bimodal distribution. As mentioned by Uddin et. al, 2019, the radar backscattering characteristics of flood water differ from nonwater bodies in different SAR polarizations and showed that optimum backscatter ranges for inundated areas are between -24 and $-17 \mathrm{~dB}$ in $\mathrm{VH}$ polarization and -22 and $-13 \mathrm{~dB}$ in $\mathrm{VV}$ polarization. Therefore, simple histogram-based thresholding was used to extract water areas in each SAR image of different polarization.

\section{- Google Earth Engine (GEE)}

Given the high amount of image download and processing required, it is clear that desktop-based systems are not suitable for providing fast rendering services critical to a flood response. Today, the Google Earth Engine platform hosts huge dataset to analyse and visualize geospatial dataset for different aims. Therefore, in this study, a GEE-based approach was used to assess flooding occurances between 2015-2018 using NDWI and calibrated SAR db values.

\section{RESULTS}

\subsection{Optical data analysis}

Optical Landsat 8 and Sentinel 2 images were selected from the GEE archive for 2015 - 2018 by filtering with a percentage of cloud coverage of less than 10\%. In this context, 52 (from 157) and 145 (from 408) images were used for Landsat and Sentinel 2 satellites, respectively. Then, NDWI time series for this area were created (Figure 5).

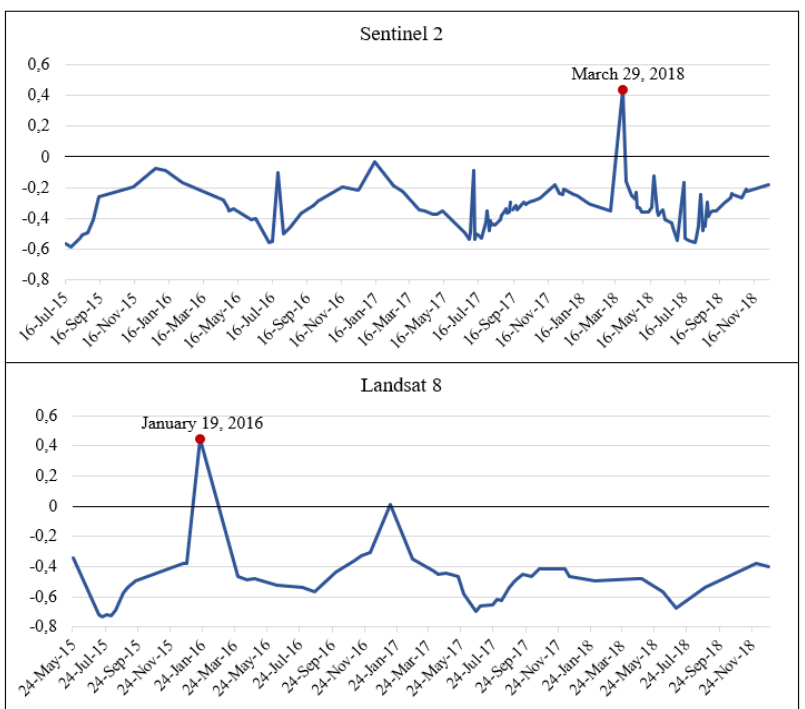

Figure 5. NDWI time series of the optical images used.

Changes in water level can be easily seen in Figure 5, but the main floods (e.g. occurred on January 19, 2016 and March 29, 2018) can be observed within the time series, only if optical images were obtained immediately after the floods. In other words, optical data may not always be so efficient in flood analysis because it is not possible to obtain optical images during overflow due to heavy cloud mass.

\subsection{SAR data analysis}

In this study, 552 Sentinel images were used; and the water and non-water areas were rather well separated in VV polarization with thresholds of $-20 \mathrm{~dB}$. In other words, all flood risk events were extracted from the GEE archive for 2015 - 2018, taking into account the calibrated Sentinel 1 Level-1 SAR values of less than $-20 \mathrm{~dB}$ (Figure 6); and these images were verified by comparing with the data in Turkish Disaster and Emergency Management Authority (AFAD) website, and digital media news. As shown in Table 2, some images matched known flood events, some did not. In addition, flood-affected areas were calculated for each event identified in the selected area.

Table 2 shows that the largest flood-affected area occurred after the flood of 2 February 2015, which was confirmed by AFAD and digital media. However, in some floods, digital media and AFAD website do not contain any information Likewise, some floods take place on digital media, but are not available on the AFAD website. It may be concluded from the table that only large flood events (approx. average 1500 hectares) causing great damage, have been reported. 


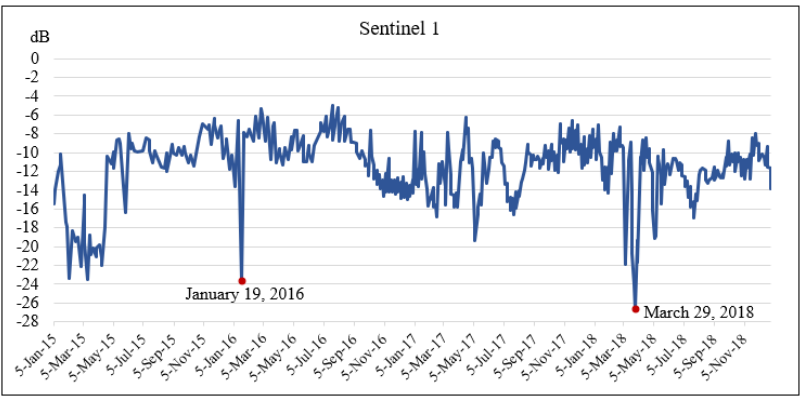

Figure 6. The calibrated Sentinel 1 Level-1 SAR time series covering the period $2015-2018$.

\begin{tabular}{|l|c|c|r|}
\hline $\begin{array}{c}\text { SAR Image } \\
\text { Dates } \\
\text { (Below -20 dB) }\end{array}$ & $\begin{array}{c}\text { Flood Dates } \\
\text { (Research on }\end{array}$ & $\begin{array}{c}\text { Flood Dates } \\
\text { (from AFAD) }\end{array}$ & $\begin{array}{c}\text { Flood } \\
\text { Affected } \\
\text { Areas (ha) }\end{array}$ \\
\hline Feb 5, 2015 & Feb 2, 2015 & Feb 2, 2015 & \\
\hline March 1, 2015 & No information & No information & 2323.02 \\
\hline March 13, 2015 & & No information & \\
\hline March 19 & Marc.82 \\
\hline March 25,2015 & March 25, 2015 & March 25, 2015 & 1402.19 \\
\hline March 30,2015 & & & 1698.05 \\
\hline March 31,2015 & & & 1725.91 \\
\hline April 11,2015 & No information & No information & 1327.26 \\
\hline April 12,2015 & No information & No information & 1051.94 \\
\hline & January 18, 2016 & January 18, 2016 & \\
\hline January 19, 2016 & & & 1893.48 \\
\hline March 8, 2018 & March 8, 2018 & No information & 745.46 \\
\hline March 9, 2018 & & & 776.85 \\
\hline March 21, 2018 & No information & No information & 685.35 \\
\hline & March 25,2018 & March 25,2018 & \\
\hline March 26, 2018 & & & 936.98 \\
\hline March 27, 2018 & & & 1191.19 \\
\hline April 2, 2018 & No information & No information & 1314.97 \\
\hline
\end{tabular}

Table 2. Comparison of floods obtained from SAR images with digital media and AFAD data.

Table 3 shows the flow values of all overflow stages (i.e. before, during and after the flood) measured at the flow monitoring stations and the precipitation data obtained from the Edirne Meteorological Station. In the table, the dates framed in blue show the dates of the floods. The Directorate of State Hydraulic Works (DSI) performs flow measurement many times a day and they are categorized according to the alarm levels that displayed in different colors. The alarm levels for each station are determined according to the station's various parameters and are announced when critical values are reached (Url-4). It is seen from table that no alarm was given by DSI for flood events in March 2015 (listed in Table 2), although large areas were affected.

Flow rates on February 2-3, 2015 and January 17-18, 2016 are the highest flow rates measured by the 11th Regional Directorate of Water Affairs. The flood on February 2, 2015, described as "the disaster of the century" due to heavy rainfall in Bulgaria and Greece, led to huge increase in the flow of the Tundzha and Maritsa rivers (Url-5) In other words, as is known, in the event of excessive rainfall or snow melting, the sudden rising flow cannot be carried by the river beds and therefore floods occur, so this flood (i.e. dated on February 2, 2015) is due to the opening of shutters in Bulgaria dams. According to DSI, the water flow reached $2149 \mathrm{~m}^{3} / \mathrm{sec}$ on the Maritsa River and $346 \mathrm{~m}^{3} / \mathrm{sec}$ on the Tundzha River that day.

\begin{tabular}{|c|c|c|c|c|c|c|c|}
\hline \multirow{3}{*}{ Dates } & \multicolumn{6}{|c|}{ Flow $\mathrm{m}^{3} / \mathrm{sn}$} & \multirow{3}{*}{$\begin{array}{l}\text { Edirne } \\
\text { M.S. } \\
\text { Preci. } \\
\mathrm{mm} / \text { day }\end{array}$} \\
\hline & \multicolumn{3}{|c|}{ Tundzha } & \multicolumn{2}{|c|}{ Maritsa } & \multirow{2}{*}{\begin{tabular}{|l|} 
Arda \\
Ivoy.
\end{tabular}} & \\
\hline & Elh. & Sua. & Deg. & Svil. & Kiri. & & \\
\hline Feb 1, 15 & 138 & 252 & & 1052 & 894 & 1033 & 26.3 \\
\hline Feb 2, 15 & & 371 & & 1234 & 2101 & 1570 & 3.2 \\
\hline Feb 3, 15 & & 346 & & 1115 & 2149 & 860 & 0.0 \\
\hline \begin{tabular}{|l|} 
Feb 5, 15 \\
\end{tabular} & 178 & 251 & & 873 & 1443 & 235 & 0.0 \\
\hline Mar 1,15 & 127 & 137 & & 347 & 582 & 102 & 0.0 \\
\hline Mar 2,15 & 125 & 138 & & 353 & 598 & 111 & 0.0 \\
\hline Mar 3,15 & 118 & 138 & & 342 & 630 & - & 0.2 \\
\hline Mar 7,15 & 122 & 151 & & 879 & 880 & 267 & 28.4 \\
\hline Mar 8, 15 & 141 & 249 & & 941 & 1197 & 275 & 12.0 \\
\hline Mar 11,15 & 165 & 242 & & 1046 & 1338 & 381 & 0.0 \\
\hline Mar 12,15 & 161 & 224 & & 1058 & 1345 & 396 & 0.0 \\
\hline Mar13,15 & 156 & 210 & & 923 & 1345 & 339 & 0.2 \\
\hline Mar 24,15 & 120 & 144 & & 549 & 1147 & 294 & 0.0 \\
\hline Mar 25, 15 & 118 & 135 & & 526 & 972 & 271 & 0.0 \\
\hline Mar 26,15 & 115 & 133 & & 532 & 953 & 268 & 0.0 \\
\hline Mar 27,15 & 115 & 131 & & 495 & 953 & 270 & 8.6 \\
\hline Mar 30,15 & 152 & 222 & & 817 & 1338 & 639 & 0.1 \\
\hline Mar 31,15 & 156 & 188 & & 750 & 1356 & 468 & 0.2 \\
\hline Apr 11-12,15 & - & - & - & - & - & - & 0.0 \\
\hline Jan 17, 16 & & 217 & & 733 & 1000 & 645 & 62.4 \\
\hline Jan 18, 16 & & 219 & & \begin{tabular}{|l|}
729 \\
\end{tabular} & 1364 & 683 & 7.2 \\
\hline $\operatorname{Jan} 19,16$ & 110 & 117 & & 377 & 1307 & 637 & 0.0 \\
\hline Mar 1,18 & 26 & 46 & 52 & 149 & 459 & 43 & 0.0 \\
\hline Mar 7,18 & 85 & 175 & 185 & 406 & 766 & 0 & 1.2 \\
\hline Mar 8,18 & 85 & 143 & 196 & 363 & 727 & 232 & 0 \\
\hline Mar 9,18 & 80 & 132 & 188 & 374 & 739 & 0 & 5.2 \\
\hline Mar 18,18 & 33 & 60 & 78 & 218 & 475 & 241 & 0.0 \\
\hline Mar 24,18 & 101 & 182 & 202 & 421 & 801 & 267 & 6.8 \\
\hline Mar 25,18 & 103 & 185 & 222 & 413 & 886 & 264 & 3.0 \\
\hline Mar 26,18 & 104 & 180 & 236 & 406 & 875 & 264 & 0.2 \\
\hline Mar 27,18 & 111 & 226 & 284 & 614 & 1109 & 377 & 13.2 \\
\hline Mar 28,18 & 113 & 215 & 308 & 478 & 1368 & 440 & 17.8 \\
\hline Mar 29,18 & 115 & 201 & 264 & 482 & 1353 & 421 & 9.4 \\
\hline Mar 30,18 & 113 & 194 & 240 & 442 & 1258 & 388 & 0.0 \\
\hline Mar 31,18 & 104 & 175 & 219 & 359 & 1121 & 293 & 0.0 \\
\hline Apr 1,18 & 95 & 155 & 204 & 324 & 920 & 249 & 0.0 \\
\hline Apr 2, 18 & 83 & 135 & 187 & 282 & 801 & 0 & 0.0 \\
\hline Nov 20,18 & 10 & 14 & 14 & 123 & 145 & 0 & 0.0 \\
\hline Nov 28,18 & 12 & 16 & 17 & 117 & 152 & 182 & 128.5 \\
\hline Nov 29,18 & 13 & 15 & 28 & 115 & 289 & 183 & 1.8 \\
\hline \begin{tabular}{|l|} 
Nov 30,18 \\
\end{tabular} & 13 & 16 & 16 & 115 & 344 & 259 & 0 \\
\hline
\end{tabular}

Alarm Level $1 \square$ Alarm Level $2 \square$ Alarm Level 3

Table 3. Flows and precipitations measurements. 
Table 3 shows that the most affected areas due to flood are consistent with the highest measured flow rates. Compared to other flood events, it is seen that the areal extents affected by the flood were also proportional to the river flow rates.

When the flood recorded on November 28, 2018 is analyzed, it is seen that the flow values are quite low. The main reason for this flood can be explained by the excessive rainfall (128.5 $\mathrm{mm}$ /day), which is the highest rainfall since $1930-2018$. Given that the average monthly rainfall is $69.7 \mathrm{~mm}$ for the 88 -year period, it is seen that the daily precipitation amount at the time of the flood was 2 times that of the average value (Url-6). On this date, the areal extent of inundated areas was found as 279 ha.

To compare the inundated areas caused by 2 different main reasons in the study area (i.e. the opening of shutters in Bulgaria dams or local excessive rainfall), 2 images dated 5 February 5, 2015 and November 28, 2018 were taken into consideration (Figure 7).

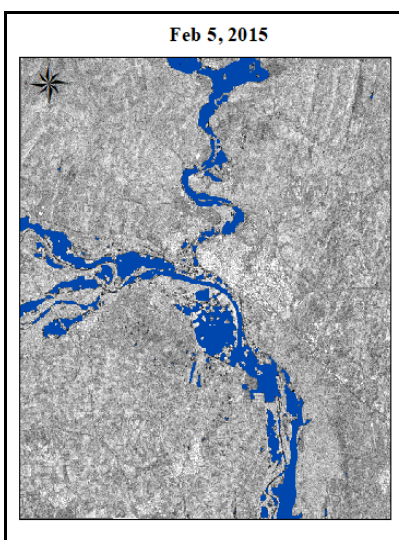

(a)

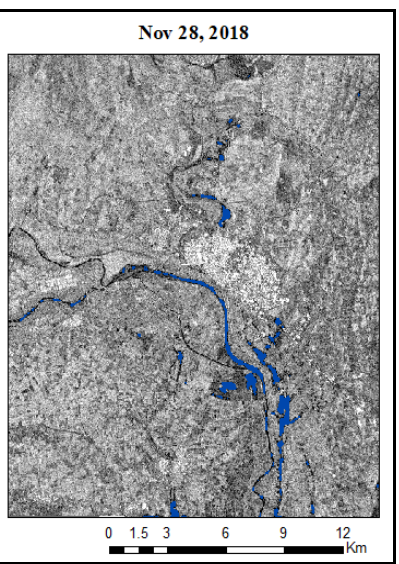

(b)
Figure 7. Comparison of inundated areas caused by 2 different floods. (a) The opening of shutters in Bulgaria dams

(b) Local excessive rainfall.

When two images were examined, it was determined that the flood-affected area as a result of the opening of shutters in Bulgaria dams was about approximately 8 times larger (2323 ha) than the other event ( $279 \mathrm{ha})$. This proves the need for a comprehensive agreement with Bulgaria to properly regulate the reservoir volumes of these dams.

\section{CONCLUSION}

Floods are among Earth's most common-and most destructivenatural hazards. It is known that the Maritsa basin, which is a cross-border and flood-producing river, has a long flood history and the number of floods in this basin have increased dramatically in the last 15 years. Although it is not clear whether this increase in flood frequency is due to climate change (i.e. meteorological causes) or the mismanagement of Bulgarian dams, however, it is clear that the drainage system and the carrying capacity of the rivers are not sufficient to prevent floods in Edirne. In this context, as stated by experts, the Bulgarian dams on these rivers need to be operated because the total flow in Edirne should not exceed $1000 \mathrm{~m}^{3} / \mathrm{s}$.
The Turkish Directorate of State Hydraulic Works performs daily flow measurements and classifies them according to the alarm levels determined according to the various parameters of the station. As shown in this study, the regions most affected by the flood are consistent with the highest measured flow rates, and it appears that the flood affected areas are proportional to river flow rates compared to other flood events.

This study aims to demonstrate a rapid risk assessment for potential damage assessment by analysing optical and active satellite image data automatically on the GEE platform. As shown in this study, there are two main causes of floods in the basin (i.e. the opening of shutters in Bulgaria dams or local excessive rainfall), and the magnitude of the damages caused by them is different. It is seen that the damage caused by the opening of shutters in Bulgaria dams was about 8 times greater than the other.

Based on the findings of this preliminary study, it can be concluded that geo-information technologies, including remote sensing, provide prompt information for effective decisions for flood disaster management of cross-border areas such as the Maritsa river basin. Cloud-based computation environments, such as the GEE platform, proved to be particularly valuable for a rapid flood-related emergency response and for assessment of flood damages. For future work, we will consider to use more data available in other cloud computing resources, such as those offered by NASA Earth Exchange (NEX), or Amazon Web Service (AWS).

\section{ACKNOWLEDGEMENTS}

We express our gratitude to Sadettin Malkaralı, Edirne Branch Manager of 11th Regional Directorate of State Hydraulic Works, for flow data supply and his guidance.

\section{REFERENCES}

CRED, 2015. The Human Cost of Weather-Related Disasters 1995-2015; Technical Report; Centre for Research on the Epidemiology of Disasters; UN Office for Disaster Risk Reduction (UNISRD): Geneva, Switzerland.

INWEB (International Network of Water Environment Centres for the Balkans), Internationally Shared Surface Water Bodies in Balkan Region

http://www.inweb.gr/workshops2/sub_basins/13_14_15_Evros_ Ardas_Ergene.html, Accessed August 1, 2019

McFeeters, S. K., 1996. The Use of the Normalized Difference Water Index (NDWI) in the Delineation of Open Water Features. International Journal of Remote Sensing, vol. 17, no. 7, pp. 1425-32.

Sezen, N., 2007. River Basin Flood Management: Meriç River Flood and Turkish-Bulgarian Cooperations, International Congress on River Basin Management. State Hydraulic Works DSI, Turkey.

Shen, X., Wang, D., Mao, K., Anagnostou, E., Hong, Y., 2019. Inundation Extent Mapping by Synthetic Aperture Radar: A Review. Remote Sensing, 11(7), 879. 
Turoglu, H., Uludag, M., 2010. Floods and flashfloods in Edirne (Turkey). International Multidisciplinary Scientific GeoConference: SGEM: Surveying Geology \& mining Ecology Management, 2, 9.

Uddin, K.; Matin, M.A.; Meyer, F.J., 2019. Operational Flood Mapping Using Multi-Temporal Sentinel-1 SAR Images: A Case Study from Bangladesh. Remote Sensing, 11, 1581.

Yildiz, D., 2011. Obligation for international cooperation in the water management of the Meriç River basin. Middle East Strategic Research Center, ORSAM Water Research Report, (44).

Url-1: https://landsat.gsfc.nasa.gov/landsat-8/, Accessed July 19, 2019.

Url-2: https://sentinel.esa.int/web/sentinel/home, Accessed July 19,2019

Url-3: http://www.hidropolitikakademi.org/transboundaryfloods-over-meric-maritzaevros.html/3, Accessed July 18, 2019

Url-4: edirnenehir.dsi.gov.tr, Accessed July 19, 2019

Url-5: http://www.hurriyet.com.tr/gundem/edirnede-yuz-yilinfelaketi-28104747, Accessed July 19, 2019

Url-6: https://www.mgm.gov.tr/veridegerlendirme/il-ve-ilceleristatistik.aspx?m=EDIRNE, Accessed July 16, 2019 